\title{
Die Neuregelung der Strafbarkeit des Jahresabschlussprüfers
}

\author{
Ein Vorschlag de lege ferenda zur Erfassung der strafwürdigen und \\ strafbedürftigen Konstellationen von beruflichem Fehlverhalten des \\ Jahresabschlussprüfers
}

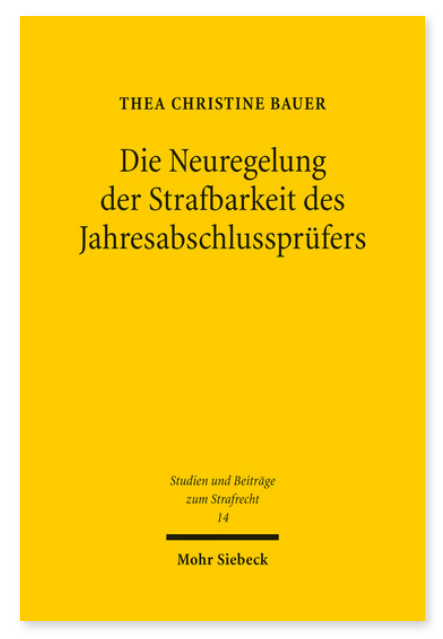

2017. XXV, 360 Seiten. StudStR 14

ISBN 978-3-16-155405-6

DOI 10.1628/978-3-16-155405-6

eBook PDF 94,00€

ISBN 978-3-16-155073-7

fadengeheftete Broschur 94,00€
In den vergangenen Jahrzehnten wurden die Kapitalmärkte im In- und Ausland durch eine Flut von Bilanzskandalen erschüttert, beispielhaft genannt sei nur der FlowTex-Skandal. Häufig hatten dabei die Jahresabschlussprüfer die ganz massiven Bilanzfälschungen des Managements nicht aufgedeckt, sondern vielmehr uneingeschränkte Bestätigungsvermerke erteilt. Strafrechtliche Verurteilungen der Jahresabschlussprüfer blieben in der Folge jedoch aus. Thea Christine Bauer befasst sich zunächst mit der Frage, warum der eigens für diese Situation geschaffene § 332 HGB und die einschlägigen Tatbestände des Kernstrafrechts auf den Jahresabschlussprüfer in der Praxis faktisch keine Anwendung finden. Anschließend analysiert sie die Strafwürdigkeit und Strafbedürftigkeit der verschiedenen Formen prüferischen Fehlverhaltens. Auf der Grundlage der gefundenen Ergebnisse entwickelt sie hiernach den Vorschlag eines § 332 HGB n.F. und beleuchtet diesen ausführlich unter verfassungsrechtlichen und praktischen Gesichtspunkten.

Thea Christine Bauer Geboren 1985; Studium der Rechtswissenschaften an der Bucerius Law School in Hamburg und der University of Indiana, Maurer School of Law (USA); 2012 Erste Juristische Staatsprüfung in Hamburg; Wissenschaftliche Mitarbeiterin am Lehrstuhl Strafrecht I der Bucerius Law School; Referendariat in Hamburg; 2016 Promotion; 2017 Zweite Juristische Staatsprüfung.

Jetzt bestellen:

https://mohrsiebeck.com/buch/die-neuregelung-der-strafbarkeit-des-jahresabschlusspruefers-9783161554056?no_cache=1 order@mohrsiebeck.com

Telefon: +49 (0)7071-923-17

Telefax: +49 (0)7071-51104 